\title{
Análise do plano de fechamento de mina no plano de aproveitamento econômico de uma jazida - uma exigência da NRM-20
}

\author{
Analysis of the mine closure plan in the economic exploitation \\ plan for an ore body - an NRM-20 requirement
}

\section{Alessandro Gomes Resende \\ Engenheiro de Minas Mestre em Engenharia Mineral pelo PPGEM / EM / UFOP \\ E-mail: alessandrogr@hotmail.com}

Hernani Mota de Lima

Prof. do Departamento de Engenharia de Minas/EM/UFOP

E-mail: hernani.lima@ufop.br

José Cruz do Carmo Flôres

Prof. do Departamento de Engenharia de Minas/EM/UFOP

E-mail: jcruzflores@demin.ufop.br

\section{Resumo}

O Código de Mineração do Brasil define lavra como o conjunto de operações necessárias para o aproveitamento industrial da jazida, as quais incluem a explotação (lavra) e o beneficiamento. Tais operações são apresentadas no Plano de Aproveitamento Econômico (PAE), que deve demonstrar a exeqüibilidade técnica e econômica da lavra de uma jazida para obtenção do Alvará (Portaria) de Lavra. Desde 2002, a inclusão do plano de fechamento de mina no PAE passou a ser uma exigência, conforme a NRM-20. Esse estudo investigou a aplicabilidade da exigência do plano de fechamento de mina nos PAEs protocolizados no DNPM. Para tal, foram avaliados 30 PAEs protocolados no DNPM, após a publicação da NRM. Embora seja uma exigência da NRM-20, esse estudo possibilitou observar que nenhuma das minas estudadas teve um plano de fechamento incluído no PAE. Também não possibilitou observar, em momento posterior, quando de alguma atualização, se os PAEs apresentados tenham sido aprovados e se o Alvará de Lavra tenha sido outorgado. Mesmo não havendo planos de fechamento incluídos, 14 PAEs apresentaram, na análise econômica da jazida, algum custo com fechamento de mina. Neles, a relação Custo Estimado de Fechamento/CAPEX mostra grande dispersão de valores. Por outro lado, em 16 PAEs não há qualquer estimativa de custos associados ao fechamento de mina. Esse estudo ressalta a falta de diretrizes do governo para a avaliação dos PAEs com foco no plano de fechamento de mina. E, por parte das empresas de mineração, destaca a falha em se considerar o custo de fechamento como o custo de contratação de consultoria para elaboração do plano de fechamento.

Palavras-chave: Fechamento de mina, plano de aproveitamento econômico, NRM-20.

\begin{abstract}
The Brazilian Mining Code defines mining as the set of operations required for the industrial exploitation of a mineral deposit, which includes mining and processing. In order to obtain a Mining Permit, such operations should be presented in an Economic Exploitation Plan (EEP) which should demonstrate the technical and economic feasibility of mining a deposit. Since 2002, the inclusion of a mine closure plan in the EEP has been a requirement, as the NRM-20. This study investigated the applicability of this requirement's inclusion in the EEP
\end{abstract}


Análise do plano de fechamento de mina no plano de aproveitamento econômico de uma jazida ...

from proposals presented to DNPM. Thirty EEPs were analyzed after the publication of the NRM. Although it is a requirement of $N R M-20$, this study demonstrates that no one of the studied mines had a closure plan included in the EEP, or thereafter, as an update. And, that those EEPs were approved and the mining permit granted. Even with no closure plans included, 14 EEPs presented some closure cost for economic analysis. In these, the Estimated Closure Cost (ECC) had greatly dispersed values. On the other hand, in 16 EEPs there was no cost estimate associated with mine closure. This study highlights the lack of government guidelines for the evaluation of EEPs focused on a mine closure plan. And, that the mining companies fail to consider the hiring of consultants for closure plan design as a mine closure cost.

Keywords: Mine closure, economic exploitation plan, NRM-20.

\section{Introdução}

Entende-se por lavra o conjunto de operações coordenadas objetivando o aproveitamento industrial da jazida, desde a extração de substâncias minerais úteis que contiver, até o beneficiamento (Art. 36 do Código de Mineração). Tais operações são consubstanciadas no Plano de Aproveitamento Econômico (PAE), que constitui um dos elementos de informação e prova dentre os vários citados no Cap.III, Art. 38, inciso VI, do Código de Mineração. O Artigo 39 elenca os itens que devem constar num PAE (Freire, 2001). O PAE apresenta a concepção técnica e econômica de processo de aproveitamento de reservas minerais definidas em relatório de pesquisa aprovado pelo DNPM.

O PAE de uma futura mina deve incluir informações, com razoável certeza, da vida útil da mina, bem como dos fatores técnicos, econômicos, sociais e ambientais que poderão afetar a viabilidade do aproveitamento do bem mineral e listar tendências tecnológicas e culturais que ampliarão ou reduzirão o interesse público pelo bem mineral a ser explotado. Portanto, a fase de exaustão da mina deve ser contemplada com a devida importância no PAE, de forma a evitar ou minimizar sérios impactos, locais e regionais (Flôres, 2006). Os elementos de instrução do PAE são apresentados no Código de Mineração. Cabe ao DNPM a análise criteriosa do PAE proposto. Caso este não seja satisfatório, compete ao órgão exigir a sua complementação e, persistindo a deficiência, indeferir o requerimento do título de concessão de lavra (Código de Mineração, Art. $41, \S 2^{\circ}$ a $4^{\circ}$ ), tendo, como conseqüência ,a não implantação do projeto. O prazo dado pelo DNPM ao titular do direito minerário para atendimento às exigências é de sessenta dias, contados a partir da data de publicação no DOU, podendo ser prorrogado antes do prazo final (Ribeiro, 2006).

Uma reserva mineral em si não dispõe de valor econômico, mas tão somente de um valor potencial, difícil de ser mensurado dada a peculiaridade do setor. O seu uso racional, baseado em projeto técnico e econômico de aproveitamento do bem mineral, aprovado pelo DNPM, é que lhe dará um valor econômico (Souza \& Herrmann, 1980). Um corpo mineral do qual não se tenha claramente demonstrado a plena exeqüibilidade técnica e econômica não deveria jamais ter o PAE aprovado pelo órgão federal (Poveda, 2007).

A emissão da Portaria de Lavra, pelo DNPM, está condicionada à aprovação do PAE e ao licenciamento ambiental emitido pelo órgão ambiental competente. A exigência legal do licenciamento ambiental prévio para a concessão de lavra é apenas um dos vários requisitos estipulados na lei minerária e, mesmo com a obtenção deste, não se pode defender que o requerente possua o direito de minerar, pois o DNPM poderá não outorgar o título de lavra por critérios de conveniência e oportunidade devidamente justificados (Poveda, 2007). Nos termos do Código de Mineração, Art. 48, a prática da lavra em desacordo com o PAE da jazida aprovado caracteriza lavra ambiciosa e resultará na aplicação de sanções pelo DNPM, que poderão ir da advertência à caducidade do título.

Em adição às exigências citadas, o órgão federal também exige que o minerador apresente o plano de fechamento de mina, quando da apresentação do PAE da jazida, de acordo com a Portaria DNPM n 237 de 18/10/2001, alterada pela Portaria DNPM n ${ }^{\circ} 12$ de 29/01/2002, que instituiu as Normas Reguladoras da Mineração (NRM), com previsão específica na NRM-20, que dispõe sobre Suspensão, Fechamento de Mina e Retomada das Operações Mineiras. O estudo teve por objetivo investigar a aplicabilidade da exigência do plano de fechamento de mina nos planos de aproveitamento econômico elaborados pela empresa cedente e protocolizados no DNPM.

\section{Metodologia}

De acordo com a legislação atual, o acesso aos processos de requerimentos de lavra depositados no DNPM só é permitido ao titular do requerimento ou a quem do titular obtiver expressa autorização. Em virtude dessa limitação ,para o presente trabalho, analisou-se um total de 30 PAEs elaborados para minas de minério de ferro, aos quais os autores tiveram acesso em virtude de autorização da titular, desde que mantidos os sigilos impostos pela empresa e com o compromisso assumido pelos autores de que os dados seriam usados única e exclusivamente na elaboração desse estudo.

A metodologia adotada, nesse estudo, compreendeu:

1. Análise de 30 PAEs liberados pela empresa, que foram protocolados no DNPM, a partir da entrada em vigor da Portaria DNPM n 237 de 18/10/2001, cujas portarias de lavra foram outorgadas, pelo Ministério de Minas e Energia, no Estado de Minas Gerais.

2. Classificação das trinta minas produtoras de minério de ferro quanto às escalas de produção, de acordo com a movimentação anual de ROM. 
3. Classificação das minas quanto à situação operacional de cada uma delas, tendo por base o ano de 2008, a saber: em operação, com lavra temporariamente suspensa ou com lavra a ser iniciada (projeto). A terceira situação se aplica aos projetos de mineração que ainda não entraram em operação, estando em fase de implantação.

4. Análise dos custos de fechamento e custos CAPEX para as minas selecionadas

\section{Resultados e discussão}

A Tabela 1 apresenta a síntese das informações referentes às trinta minas cujos PAE's foram objeto desse estudo. Uma análise da referida tabela conduz, inicialmente, a duas importantes observações. Primeiro, nenhuma dessas minas teve um plano de fechamento apresentado por ocasião da elaboração do PAE - portanto, antes da concessão da Portaria de Lavra -, ou em momento posterior, quando de alguma atualização do PAE ao longo dos anos de operação. Segundo, verifica-se que os requerimentos de lavra apresentados após a publicação das NRM's foram deferidos - ou seja - que as respectivas portarias de lavra foram outorgadas, embora os PAEs submetidos à análise e aprovação não incluíssem o plano de fechamento de mina, conforme preceitua a NRM 20. Portanto o DNPM julgou satisfatórios os PAEs apresentados que não atendiam às exigências legais criadas e impostas pelo próprio Órgão.

A Figura 1 apresenta a situação operacional das minas que tiveram os seus respectivos PAE's analisados nesse estudo. No cronograma verificado nos PAE's, as minas em fase de desenvolvimento (lavra a ser iniciada) estão com start up previsto para os próximos cinco anos.

Da Tabela 1, pode-se, também, observar os seguintes aspectos:
- Quanto ao status operacional os PAE's analisados representam desde minas em fase de exaustão até minas com uma vida útil estimada em 30 anos.

- A vida útil média das minas está entre 15 e 20 anos de operação.

- As minas com movimentação anual de ROM superiores a 15 Mt apresentam uma vida útil em média superiores a 20 anos de operação.

- As minas com movimentação anual de ROM inferiores a 10 Mt apresentam uma vida útil em média inferiores a 10 anos de operação.

Da Tabela 1, pode-se, ainda, verificar que apenas quatorze minas contemplaram na análise econômica (fluxo de caixa) algum custo com fechamento de mina, mesmo não tendo elaborado o plano de fechamento propriamente dito. No entanto, o fluxo de caixa dessas minas não mostra qualquer abertura da memória de cálculo dos gastos previstos para se fechar uma mina, o que é obvio ante a inexistência de um plano de fechamento. De fato, utilizou-se, apenas, uma verba para a rubrica fechamento de mina sem, no entanto, abrir os custos por relação de atividades como reabilitação, descomissionamento, monitoramento e manutenção.

De acordo com Bitar (1997), são raros os casos de contabilização das medidas ambientais em minerações e, mais ainda, as que discriminam os custos com recuperação de áreas. Muito provavelmente são números estimados e até mesmo baseados na experiência de operações similares, pois fica, praticamente, impossível fazer qualquer provisão de gastos para se fechar uma mina sem um plano de fechamento que contemple os investimentos plurianuais a serem feitos durante todo o período em que a mina estiver em operação, além das atividades de monitoramento e manutenção pós-fechamento.

Apesar da não abertura dos gastos com fechamento de mina, em alguns PAE's analisados foi possível calcular o percentual aplicado pelas empresas mineradoras no investimento de capital
(CAPEX) para abertura de um determinado projeto com relação ao custo com o fechamento de mina. Outras empresas consideram apenas investimentos correntes no final da vida útil da mina com o objetivo de contratação do plano de fechamento de mina.

Nesse estudo, conceituam-se os investimentos correntes como sendo a aplicação de recursos que visam a aumentar a produtividade dos ativos, melhorar a qualidade dos produtos, desenvolver projetos, realizar pesquisa e preservar o meio ambiente e/ou condições de trabalho. Já o investimento de capital (CAPEX) é a aplicação de recursos em projetos estratégicos que visam a manter ou a ampliar a posição da empresa no mercado ou a diversificar a sua atuação para outros mercados e/ou produtos. Esses projetos, via de regra, referem-se diretamente à implantação de novas unidades produtivas (Greenfield) ou expansão de capacidade das unidades existentes (Brownfield).

Os resultados da avaliação Custo Estimado de Fechamento/CAPEX para projetos em implantação, minas em operação e minas em fase de exaustão ou suspensão temporária mostram grande dispersão de valores. Para a implantação de determinado projeto, observam-se valores da relação Custo Estimado de Fechamento/CAPEX de 1,3\% a 14,8\%. No caso de minas em operação, os valores apresentam variações de $5,8 \%$ a $39,4 \%$. Para minas em fase de exaustão e com suspensão temporária de lavra, verificam-se valores ainda mais díspares de 10,4 a $90 \%$. Os resultados mostram a relação entre o custo estimado para fechamento e o CAPEX de um determinado projeto e apresenta grande disparidade, com variações significativas de mina para mina. O número de PAEs analisados não permite considerações mais precisas. Entretanto pode-se afirmar que tais disparidades ocorrem devido à natureza, à intensidade e à gravidade dos danos ambientais que deverão ser prevenidos, mitigados ou eliminados, os quais variam de mina para mina, em razão do porte do empreendimento, da gênese, da composição química e mineralógica do minério, bem como do ecossistema em 


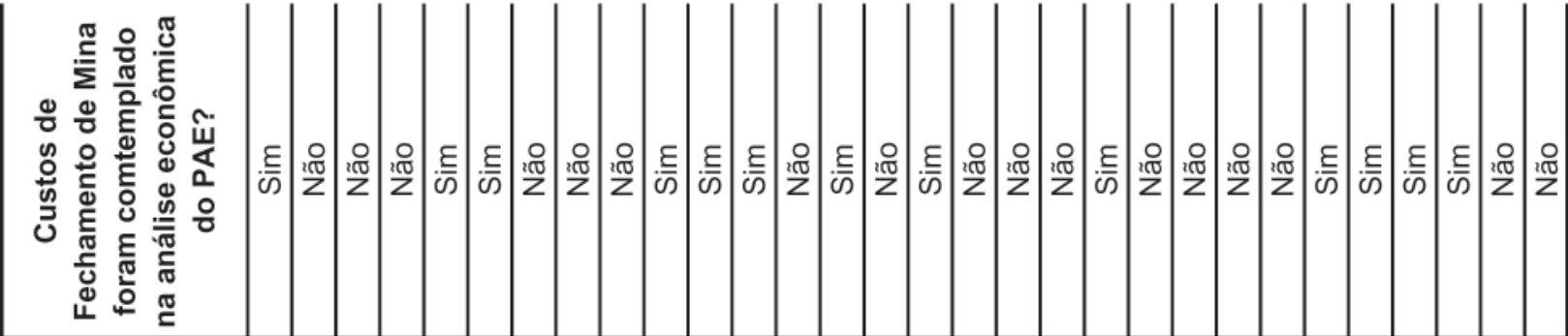

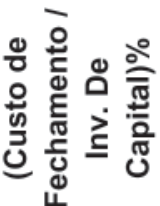

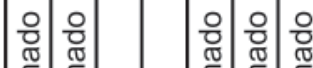

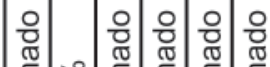

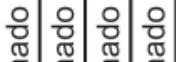

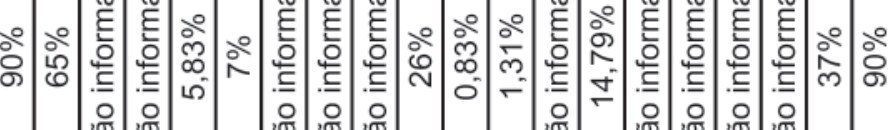

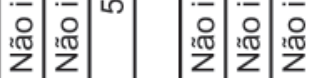

$2 \pi$
$Z$

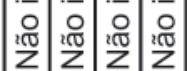

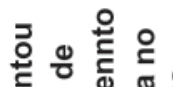

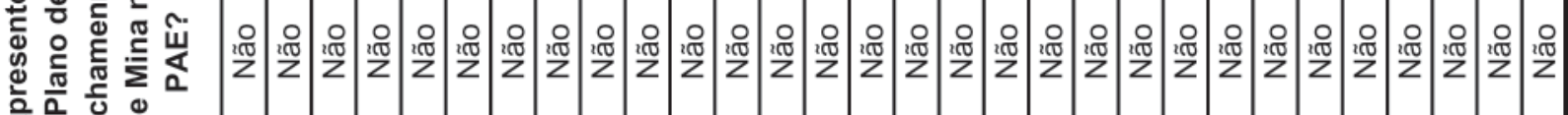
这递安

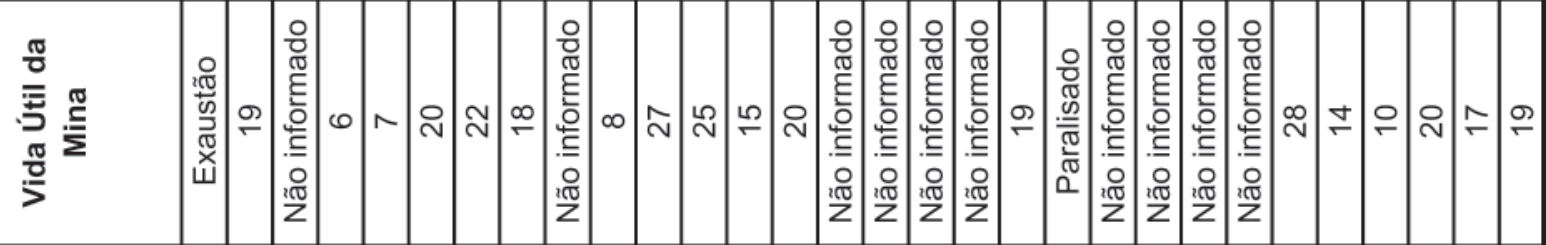

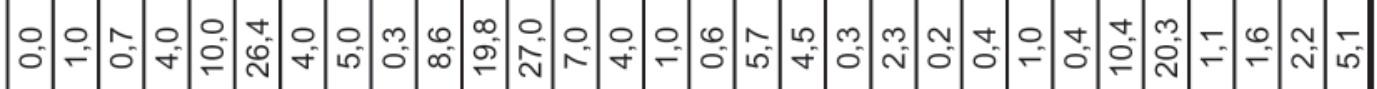

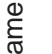

2]

$\frac{\pi}{d}$

¿

嵌

$\frac{1}{a}$

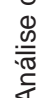

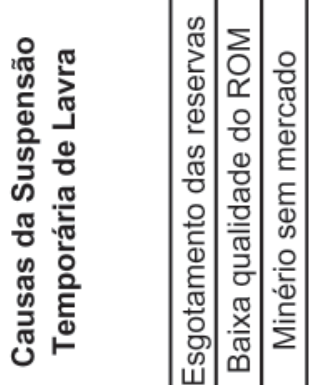

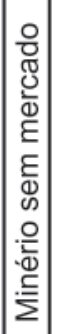

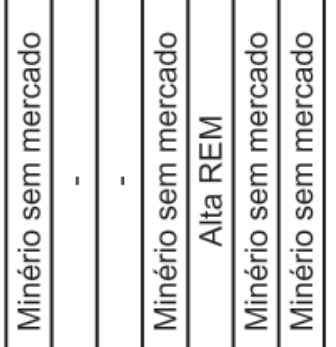

$\bar{\Phi} \bar{\Phi}$

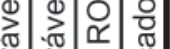
힣ㅇㅎㅇ

ш

ֻั

\section{$\approx \pi . \pi$}

-

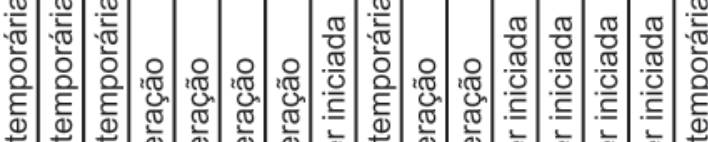

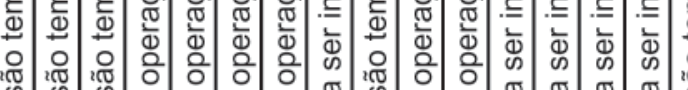

足

Ф)

के के के

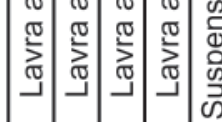

ڤ

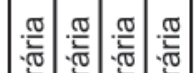

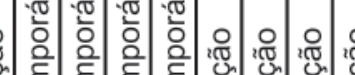

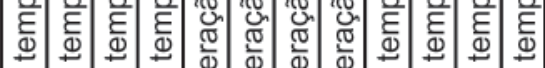

क

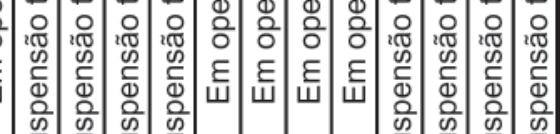

$\stackrel{\pi}{\frac{\pi}{2}}$

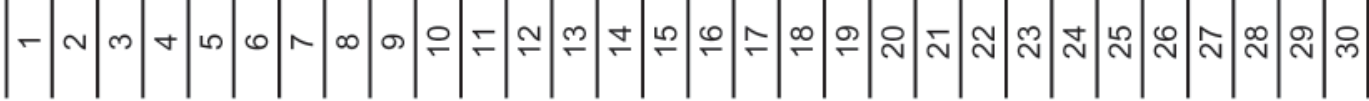


que a mina está inserida. Cabe, também, acrescentar os fatores que produzem distúrbios relacionados ao próprio despreparo e ao nível de conscientização de determinadas empresas, associados ao comportamento leniente do DNPM, no que se refere ao cumprimento de correspondentes exigências legais. A Figura 2 sumariza o percentual aplicado pelas minas na rubrica fechamento de mina em relação ao CAPEX utilizado nas análises econômicas.

Com relação às outras dezesseis minas analisadas, a situação verificada é ainda mais preocupante, pois os PAE's não fazem qualquer menção à estimativa de gastos correntes (custo operacional) e nem de gastos de capital (investimentos) associados ao fechamento de mina. Em outras palavras, o minerador ou investidor utiliza a metodologia de análise de pré-viabilidade econômica, mas desconsidera completamente os gastos com fechamento de mina, o que

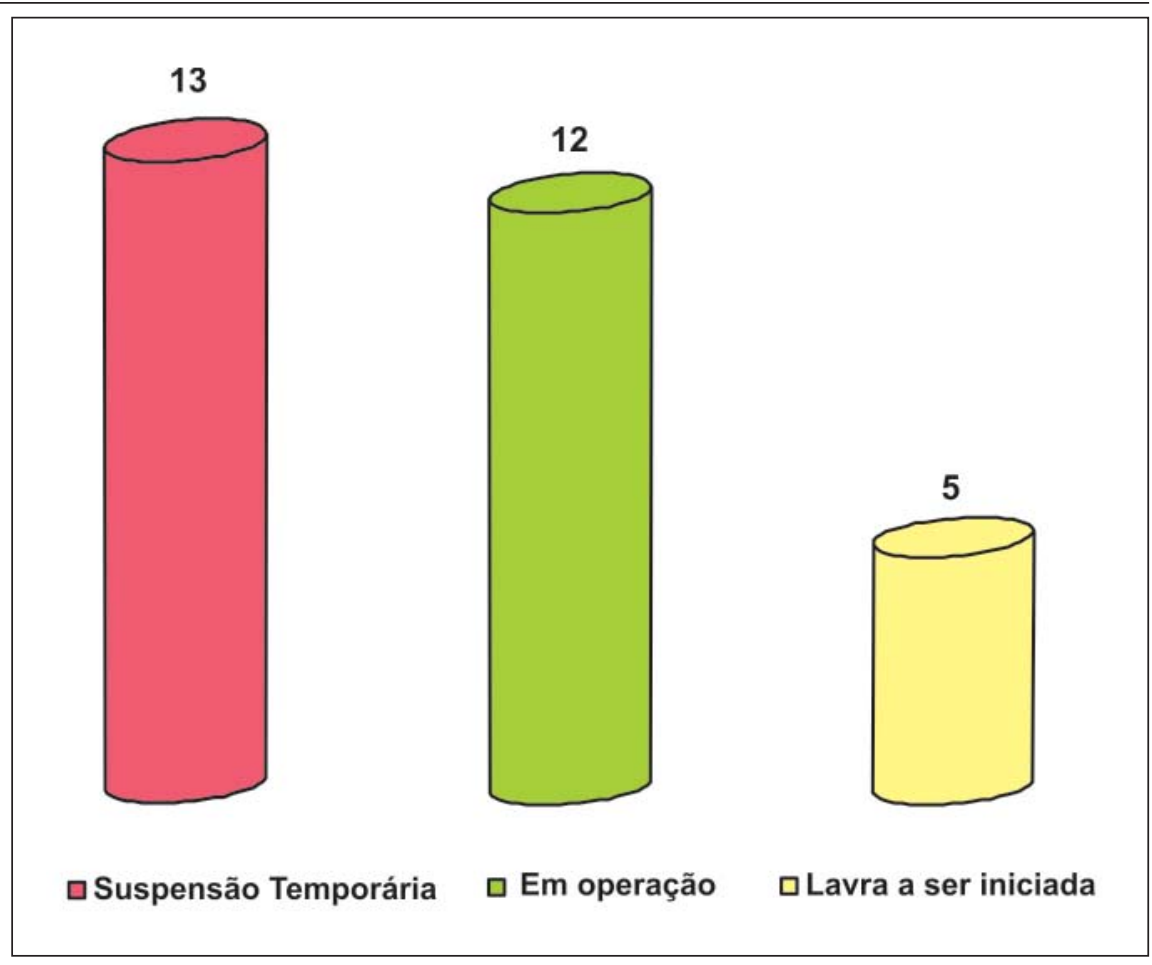

Figura 1 - Situação operacional das minas com PAE's analisados.

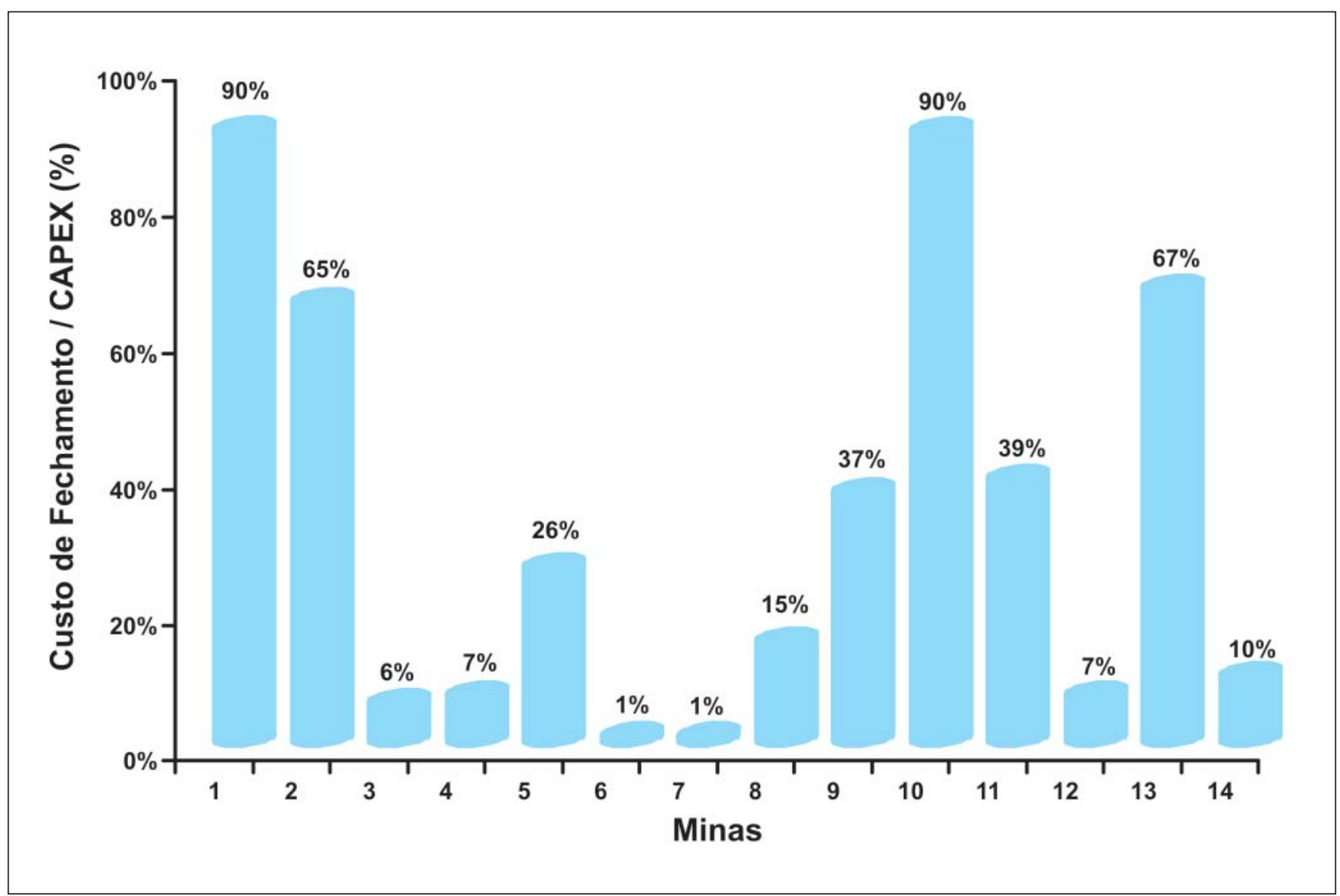

Figura 2 - Percentual aplicado no fechamento de mina em relação ao CAPEX do projeto. 
aumenta consideravelmente o grau de risco envolvido no decorrer das operações. Esse procedimento errôneo adotado pelos mineradores pode levar a grandes distorções no fluxo de caixa da empresa, principalmente quando se tratar da abertura de um novo projeto de mineração.

Além do ambiente de competição e incertezas relacionadas aos riscos de investimentos, no qual as empresas mineradoras estão inseridas, aumentam também as incertezas relacionadas aos possíveis passivos ambientais gerados. Uma das causas pode ser o fato de o minerador não ter previsto os gastos com o fechamento de mina nos estudos de viabilidade econômica do empreendimento. A consequência dessa lacuna é o comprometimento, em alguns casos, da saúde financeira da empresa no estágio final de vida da mina, cabendo ao minerador incorrer num desembolso significativo e não planejado para recuperar as áreas degradadas e fechar, satisfatoriamente, a mina.

De acordo com Sánchez (1998), nos Estados Unidos as diretrizes de contabilidade exigem a divulgação, nos balanços anuais, dos montantes estimados dos passivos ambientais. Há uma cultura de reconhecimento dos custos de fechamento de certas atividades, tornando possível que tais custos sejam levados em conta na análise de viabilidade econômica de novos investimentos. Até então, o encerramento das atividades de uma mina ou uma indústria representava um fluxo de caixa positivo, já que equipamentos, instalações e o próprio terreno podiam ser vendidos - eram ativos. Entretanto, tudo isto pode representar um passivo, ocasionalmente de monta. Isto deve ser visto como um incentivo para que as empresas tomem medidas preventivas durante a operação dos empreendimentos, através da avaliação de impacto ambiental ou outros instrumentos de planejamento, de forma a reduzir significativamente os custos de encerramento e, portanto, os passivos.

O primeiro resulta na minimização de impactos e na maximização de externalidades positivas, ao contrário do segundo de eficácia substancialmente inferior. Considerando-se a simulação técnico-econômica de um empreendimento como o de mineração, pode-se empiricamente assinalar que o valor presente do fluxo de caixa relativo ao processo virtuoso será necessariamente superior ao do processo vicioso, evidenciando que o primeiro caso conduz a uma geração de valor superior ao do segundo.

\section{Considerações finais}

O estudo mostra que dos trinta PAE's analisados, nenhum deles apresentou o plano de fechamento de mina quando do pedido de requerimento de lavra - item obrigatório de acordo com a NRM-20. O resultado encontrado permite inferir uma ausência de diretrizes no DNPM quanto à cobrança e análise de um plano de fechamento.

A análise dos PAE's permitiu observar que empresas até incluem a provisão financeira para fechamento de mina no fluxo de caixa, mas o fazem de maneira incorreta. A provisão é feita de duas formas distintas: ao final (geralmente nos três últimos anos) da vida útil da mina para contratação externa (consultoria) do plano de fechamento ou desde o início da mina, mas sem estar vinculada a um plano de fechamento de mina, mesmo que de forma conceitual.

Em Minas Gerais, a publicação em 29/11/2008 da DN COPAM nº 127 é mais uma tentativa de se estabelecer diretrizes e procedimentos para avaliação ambiental da fase de fechamento de mina, e pode ser considerada um marco importante para a questão do fechamento de mina, principalmente, se considerarmos o número de concessões de lavra existentes no Estado. Essa deliberação visa preencher também uma lacuna em Minas Gerais quanto aos procedimentos para o fechamento, aplicável a qualquer empreendimento minerário, que até então se restringia à NRM-20. A DN COPAM nº 127 já está em vigor e os novos procedimentos também, como é o caso do processo de revalidação da licença de operação, que terá mudanças a partir de $1^{\circ}$ de julho de 2009.

Não se conhece, ainda, quais serão os desdobramentos para as mineradoras. Por parte do órgão ambiental, espera-se um acompanhamento eficaz das ações a serem previstas no plano ambiental de fechamento de mina, por meio de fiscalizações e avaliação de relatórios de situação, além da aplicação das penalidades previstas na legislação ambiental vigente, nos casos de descumprimento do disposto na deliberação. Apesar do pouco tempo para avaliação dos efeitos da DN COPAM $n^{\circ} 127$, sua publicação mostra uma tendência de avanço, no que diz respeito ao fechamento de mina no Estado, com a incorporação deste tema dentro das políticas e cultura das empresas mineradoras.

\section{Referências bibliográficas}

BITAR, O. Y. Avaliação da recuperação de áreas degradadas por mineração na região metropolitana de São Paulo. São Paulo: Departamento de Engenharia de Minas e Petróleo, Escola Politécnica da Universidade de São Paulo, 1997. 183p. (Tese de Doutorado).

BRASIL. Consolidação da legislação mineral e ambiental. 10 edição atualizada e revisada / Uile Reginaldo Pinto, org. - LGE Editora, Brasília: 2006. 692p.

FLÔRES, J. C. do C. Fechamento de mina: aspectos técnicos, jurídicos e sócio-econômicos. Campinas: Instituto de Geociências, Universidade Estadual de Campinas, 2006. 309p. (Tese de Doutorado).

POVEDA, E. P. R.Aeficácia legal na desativação de empreendimentos minerários. São Paulo: Signus Editora, 2007. 238p.

RIBEIRO, C. L. Direito minerário escrito e aplicado. Belo Horizonte: Editora Del Rey, 2006. 425p.

SÁNCHEZ, L. E. A desativação de empreendimentos industriais: um estudo sobre o passivo ambiental. São Paulo: Escola Politécnica, Universidade de São Paulo, 1998. 178p. (Tese de Livre Docência).

SOUZA, P. A., HERRMANN, H. Avaliação econômica dos direitos minerários. Brasília: Divisão de Fomento da Produção Mineral, 1980. 62p. (Documento Preliminar).

Artigo recebido em 21/10/2009 e aprovado em 14/07/2010. 